\title{
Unanswered questions in central nervous system infection
}

\author{
CHAIRPERSON \\ WALTER F SCHLECH III, MD
}

\begin{abstract}
C ENTRAL NERVOUS SYSTEM (CNS) INFECTIONS ARE A MAJOR component of infectious disease practice in Canada. CNS infections are characterized by high morbidity and significant mortality even with optimal therapy. A workshop was held at La Sapiniere during the annual Canadian Infectious Disease Society (CIDS) weekend and a CNS infections workshop convened.

The major issues in CNS infections were discussed during the workshop entitled 'Unanswered questions in infectious diseases?'

Discussions were focused around commonly encountered CNS infectious disease syndromes including bacterial meningitis, brain abscess, subdural empyema, malignant otitis externa, herpes simplex encephalitis and aseptic meningitis. The major unanswered questions examined included issues of the best antimicrobial treatment, the use of combination chemotherapy, duration of therapy, best delivery methods for therapy, the role of adjunctive therapy and optimal diagnostic studies. The ultimate objective of the workshop was to study the possible development of crossCanada, multicentre CIDS-sponsored clinical trials to answer major and minor questions regarding the practical management of these conditions.
\end{abstract}

Bacterial meningitis was chosen as a paradigm for

Workshop participants: W Bowie, R Chan, G Delage, G Hammond, D Kunimotu, M Louie, J MacDonald, D McNeely, D Patrick, C Sinave, DL Tyrell

Correspondence and reprints: Dr WF Schlech III, Victoria General Hospital, 1278 Tower Road, Halifax, Nova Scotia B3H 2 Y9 purposes of discussion (1). In recent years there have been major developments in the understanding of the pathogenesis of this condition and its effect on management $(2,3)$. In addition, the development of newer antimicrobial agents, particularly third generation cephalosporins, have prompted studies to compare these agents with more traditional antibiotics such as penicillin $G$ (4). Most investigations have occurred in pediatric populations in which bacterial meningitis is seen far more commonly than in adults. Few data are available in adult populations and most management decisions have been extrapolated from studies heavily influenced by pediatric practice (5). In addition, investigators have been influenced by the preponderance of Haemophilus influenzae type B infections in most series of bacterial meningitis. $H$ influenzae type $\mathrm{B}$ infections are very rare in adults in whom pneumococcal meningitis remains the most common cause of bacterial meningitis. In addition, a greater proportion of adult meningitis is nosocomial with Staphylococcus aureus and Gram-negative organisms predominating. Appropriate antimicrobial management for these infections in adults has not been completely studied.

Most recent studies of bacterial meningitis have reported results with single agent therapies, primarily the newer beta-lactams versus ampicillin or penicillin regimens. The issue of combination therapy with agents active at different points of the bacterial life cycle or with advantageous pharmacokinetic attributes have not been done. Of particular interest would be a study of the addition of antibiotics such as rifampin or fusidic 
acid to standard synthetic penicillin (cloxacillin) therapy for Staph aureus meningitis. The standard treatment of Staphylococcus epidermidis shunt infections complicating neurosurgical procedures has been vancomycin, but no direct comparisons of combination therapy with, eg, rifampin have been developed. The rarity of these infections makes multicentre studies mandatory and might well be done under the auspices of the CIDS.

Another important issue discussed was the duration of therapy for bacterial meningitis and the best delivery method. Recommendations in the literature are varied and suggest seven to 21 days of antibiotic therapy for bacterial meningitis, but no comparative studies of duration of therapy have been carried out, particularly with the newer antimicrobial agents, including the use of well absorbed oral antibiotics. In an era where costs of therapy have become important societal questions there are significant advantages of oral treatment of bacterial meningitis following initial improvement on intravenous therapy. However, any study of duration of therapy or substitution of oral for intravenous therapy will have to take into consideration medicolegal concerns about relapse when patients are randomized to a regimen that uses less than the 'standard' duration of therapy.

Exciting developments have occurred in the past several years in the field of adjunctive therapy for bacterial meningitis (6-8). These studies, primarily in pediatric populations, have confirmed the usefulness of corticosteroid therapy to ameliorate the intense inflammatory reaction which occurs in the meninges and cerebrospinal fluid (CSF) of patients with bacterial meningitis. Most pediatricians currently consider steroids to be the 'standard' therapy for bacterial meningitis in addition to appropriate antibiotics. Few data supporting the use of corticosteroids in adults are available, primarily because of the relative rarity of bacterial meningitis in this population. This issue deserves study in a multicentre collaborative fashion and might be ideally suited to a collaboration subspecialty society effort. Other anti-inflammatory agents such as nonsteroidal anti-inflammatory drugs, methylzanthines, anti-CD18 receptor antibody, and monoclonal antibodies against interleukins or endotoxins might be considered as viable alternatives to adjunctive corticosteroid therapy.

Workshop participants agreed that a number of initiatives in the area of CNS infections could go forward under the auspices of the CIDS. One of the important advantages of a small academically oriented, subspecialty society is the opportunity to collaborate and communicate with each other in the area of clinical practice. The recognition that CNS infections are a relatively rare part of individual infectious disease practices, particularly in adult patients, makes it essential that studies involve the maximal number of clinician- investigators and employ simple protocols. Therefore, the importance of database development for relatively rare CNS infections is paramount. Simple case report forms forwarded to a central collator would allow the collection and analysis of data on the infection as a first step towards development of treatment protocols to present to potential sponsors. All CIDS members, particularly those interested in the area of treatment of CNS infections, could participate. The database itself would likely be worthy of publication because of the large case series that would be developed in its collection. In addition, retrospective analysis of the data in terms of outcomes such as morbidity and mortality could be done comparing treatment regimens and the use of adjunctive therapies.

Several potential clinical trials were discussed. In pneumococcal meningitis a comparison of a third generation cephalosporin versus penicillin $\mathrm{G}$ would be appropriate. A more pressing question would be a study of the use of corticosteroids in adults patients with bacterial meningitis. Several elements of design of these randomized controlled trials were discussed.

The idea of a specimen bank was also mentioned. CIDS members submitting case report forms for database development would be encouraged to retain organisms, serum and an aliquot of CSF at their hospital. Most CIDS members, even those in private practice, would have the ability to arrange for safe keeping of such specimens. A central locator file with the database would be developed to identify the specimen and its location so that investigators with a specific interest in. for example, susceptibility patterns across Canada would have access to the locater and request subcultures of serum or CSF for appropriate studies.

The group concluded that:

- a CNS study group should be formed within the CIDS membership;

- data forms for collection of information on bacterial meningitis and other CNS infections should be developed and examined by the group;

- principal investigators for particular studies should be identified by the study group; and

- funding issues need to be considered.

Some studies, particularly those involving extremely rare infections such as brain abscess, might remain 'orphans' and may have to be funded by overhead costs from other investigations (9-12). Other studies, such as direct comparisons of drugs for more common infections such as bacterial meningitis may well be suitable for pharmaceutical sponsorship. Collection of the descriptive data on various CNS infections in Canada would depend to a great extent on the willingness of the cIDs membership to complete and forward simple case report forms on all patients with CNS infections seen in their practice. It might be appropriate to consider small honoraria for submission of cases to compensate for the time involved in supplying the data requested. 


\section{REFERENCES}

1. Lambert HP. Unresolved problems in meningitis. J Antimicrob Chemother 1989;24:97-102.

2. Tunkel AR, Wispelwey B, Scheld WM. Bacterial meningitis: Recent advances in pathophysiology and treatment. Ann Intern Med 1990; 1 12:610-23.

3. Saez-Llorens X, Ramilo O, Mustafam M, et al. Molecular pathophysiology of bacterial meningitis: Current concepts and therapeutic implications. J Paediatr 1990;116:671-84.

4. Cherubin CE, Eng RHK, Norrby R, et al. Penetration of newer cephalosporins in the cerebrospinal fluid. Rev Infect Dis 1989;11:526-648.

5. McCracken GH. Current management of bacterial meningitis. Pediatr Infect Dis J 1989;8:919-21.

6. Tauber MG, Sande MA. Dexamethasone in bacterial meningitis: Increasing evidence for beneficial effect. Pediatr Infect Dis J 1989;8:842-5.

7. Anon. Steroids in meningitis. Lancet 1989;ii:1307-8.

8. Tuomanen E. Adjuncts to the therapy of bacterial meningitis. Pediatr Infect Dis J 1990:9;782-3.

9. Wispelwey B, Sheld WM. Brain abscess. Clin Neuropharmacol 1987;10:483-510.

10. Saez-Llorens X, Umanan MA, Odio CN, et al. Brain abscess in infants and children. Paediatr Infect Dis $\mathrm{J}$ 1989;8:449-58.

11. Patrick CC, Kaplan SL. Current concepts in the pathogenesis and management of brain abscesses in children. Paediatr Clin North Am 1988;35:625-36.

12. Donald FE. Treatment of brain abscess. J Antimicrob Chemother 1990;25:310-2. 


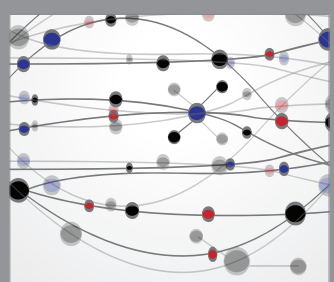

The Scientific World Journal
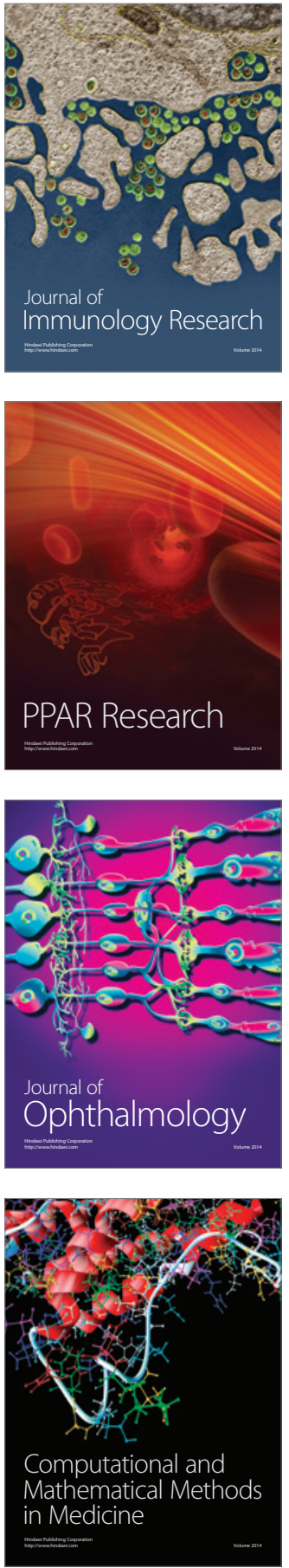

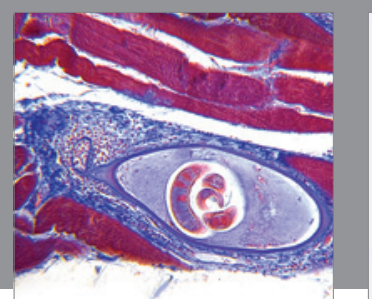

Gastroenterology Research and Practice

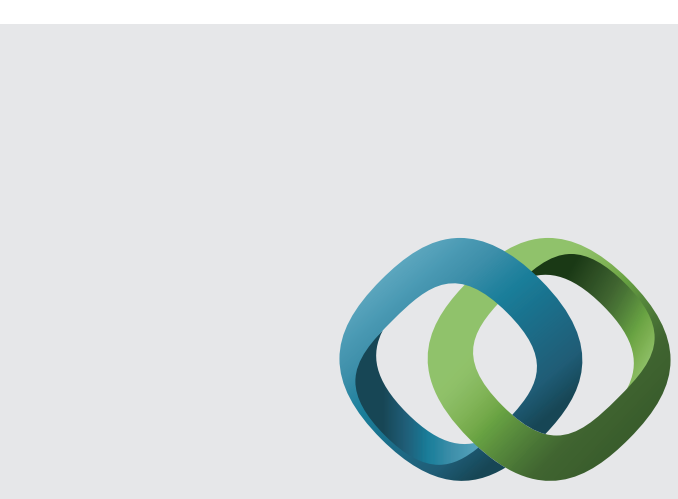

\section{Hindawi}

Submit your manuscripts at

http://www.hindawi.com
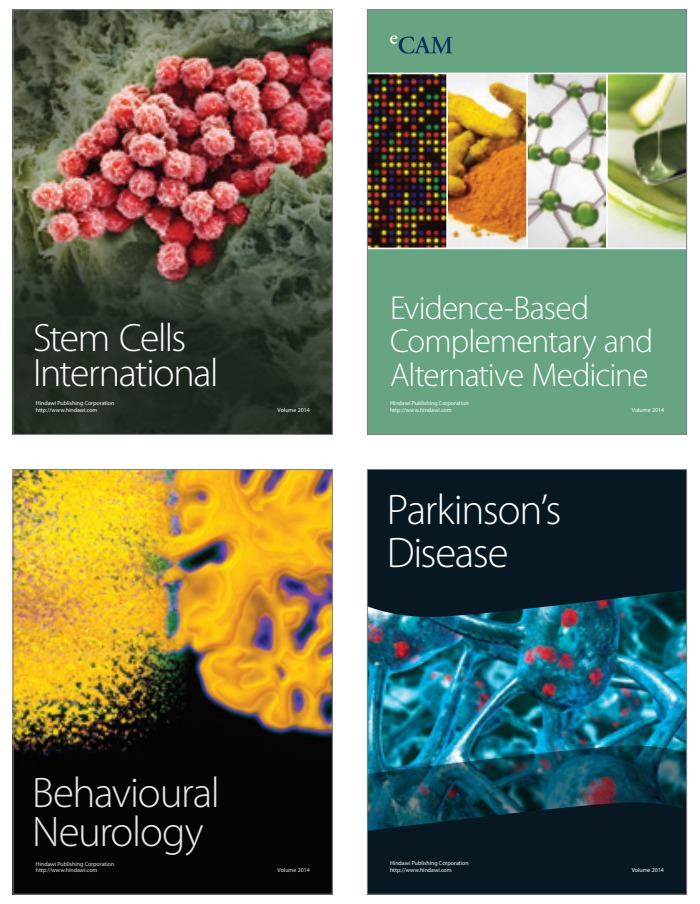
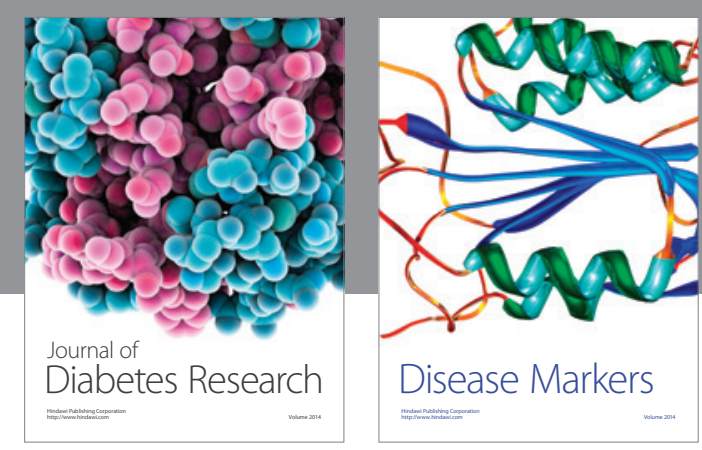

Disease Markers
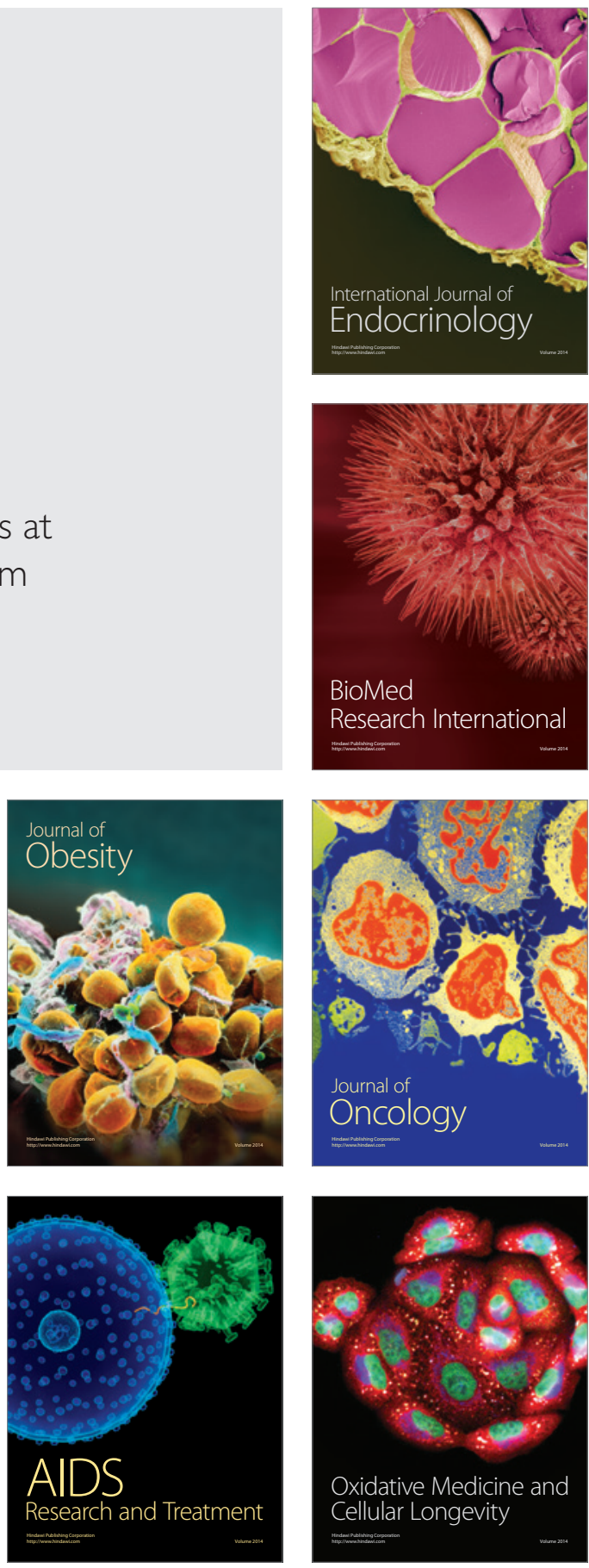